\title{
Effects of basal media, salt concentrations, antioxidant supplements and co-effects on the Agrobacterium- mediated transformation efficiency in maize
}

\author{
Hewei $\mathrm{Du}^{12}$, Huixia $\mathrm{Wu}^{3}$, Jianbing $\mathrm{Yan}^{1}$ and Jiansheng $\mathrm{Li}^{1 *}$ \\ ${ }^{1}$ China Agricultural University, National Maize Improvement Center of China, Beijing 100193, P.R.China. \\ ${ }^{2}$ The College of life science, Yangtze University, Jingzhou, Hubei 434025, P.R.China. \\ ${ }^{3}$ International Maize and Wheat Improvement Center (CIMMYT), Apdo. Postal 6-641, 06600 México, D.F., México. \\ Accepted 15 January, 2010
}

\begin{abstract}
Transformation efficiency enhancement in maize Agrobacterium-mediated transformation was tested using four different basal media, five levels of $\mathrm{N} 6$ salts, two antioxidants and copper sulfate. In the absence of the antioxidants L-cysteine and dithiothreitol (DTT), the frequencies of transient GUS expression was higher using Linsmaier and Skoog (LS) and Murashige and Skoog (MS) media as an alternative to Chu (N6) and Ducan (D). N6 basal medium exhibited better performance in the presence of antioxidants than MS, LS and D basal media. Five different levels of N6 medium salts $(10,30,50,70$ and $100 \%$ ) were tested, and the highest transformation efficiency was $15.9 \%$ under a $50 \%$ salt concentration, followed by $6.4 \%$ transformation efficiency with 70 and $3.2 \%$ under $100 \%$ salt conditions. More than $95 \%$ of infected immature embryos exhibited GUS staining under 10 and $30 \%$ salt concentrations, however none of the embryos developed into embryogenic callus, indicating that low salt levels favored T-DNA delivery, but not stable transformation. Additions of DTT or L-cysteine, or a combination of L-cysteine and DTT, showed a significant improvement in the frequency of transient GUS expression, however increases were not observed with independent $\mathrm{CuSO}_{4}$ treatments. Polymerase chain reaction (PCR) and Southern-blot analysis confirmed T-DNA integration into the maize genome.
\end{abstract}

Key words: Maize (Zea mays L.), Agrobacterium tumefaciens, transformation.

\section{INTRODUCTION}

The maize genome project has been completed and the draft sequence represents a vast repository of genomic data that is now readily available (Gore et al., 2009).

*Corresponding author. E-mail: lijiansheng@cau.edu.cn. Tel: 86-10-62732442. Fax: 86-10-62733808.

Abbreviations: N6, Chu medium; MS, Murashige and Skoog medium; LS, Linsmaier and Skoog medium; D, Ducan medium; 2,4-D, 2,4-Dichlorophenoxyacetic acid; MES, 2-(N-Morpholino) ethanesulfonic acid; DTT, Dithiothreitol; NAA, $\alpha-N a p h t h a l e n e$ acetic acid; 6-BA, N6-benzylaminopurine; CTAB, Cetyltrimethyl ammonium bromide; DIG, Digoxin; PVP, Polypyrrolidone; GUS, $\beta$-Gluceronidase gene; Bar, Bialaphos resistance gene.
However, research continues to annotate sequences to ascertain gene function in maize. Genetic transformation is considered one of the most direct and effective strategies to determine gene function in plants. Microprojectile bombardment (Gordon-Kamm et al., 1990) and Agrobacterium tumefaciens-mediated transformation (Ishida et al., 1996) are two popular methods that are currently used in maize transformation. Many studies have shown that high-copy number and extensive rearrangement of foreign DNA are frequently identified in transgenic plants by microprojectile bombardment, which often leads to transgenic silencing and unstable inheritance (Register et al., 1994; Shou et al., 2004). Therefore, high transformation frequency of maize mediated by $A$. tumefaciens has been reported as the method of choice for the delivery of 


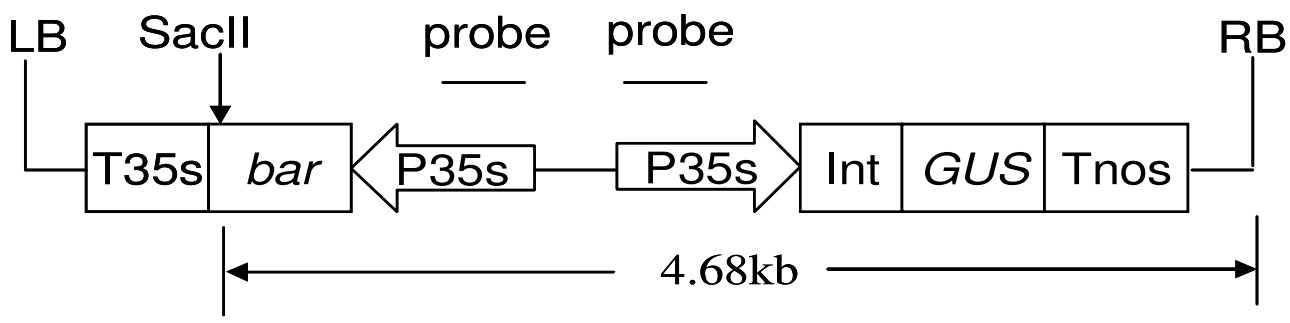

Figure 1. pCAMBIA3301. LB and RB diagram: left and right borders of the T-DNA; P35s: CaMV35s promoter; T35s and Tnos: CaMV35s terminator and nopline synthase gene terminator; bar: bialaphos resistance gene; GUS: $\beta$-gluceronidase gene.

exogenous genes into the maize genome.

$A$. tumefaciens-mediated transformation is the preeminent method for plant genetic transformation due to several advantages, including high efficiency, low-copy number, large DNA segments, low rearrangement rate and low cost (Ishida et al., 1996; Hansen and Wright, 1999). Initially, this method was only successfully applied in dicotyledonous plant genetic transformation, because monocotyledonous plants were not naturally susceptible to $A$. tumefaciens. Consequently, efforts to extend the host range of Agrobacterium to monocotyledonous plants were achieved and $A$. tumefaciens-mediated transformation was applied in monocots (Hernalsteens et al., 1984; Hooykaas-Van Slogteren et al., 1984). Subsequently, it was successfully implemented in several economically important monocotyledonous plants, such as rice (Hiei et al., 1994), wheat (Cheng et al., 1997), maize (Ishida et al., 1996) and barley (Tingay et al., 1997). High throughput genetic transformation systems in maize were developed using super binary vector systems and transformation frequency was approximately $40 \%$ (Zhao et al., 2001). However, transformation frequency was still low relative to standard binary vector systems, even under the improved co-culture conditions in maize (Frame et al., 2002). Therefore, further improvements in transformation efficiency in standard binary vector systems are still necessary.

Several factors can affect $A$. tumefaciens-mediated transformation efficiency, including co-cultivation period and temperature, co-cultivation medium $\mathrm{pH}$, host genotype, explant type and source, Agrobacterium strain and vector, and components of the medium (Huang and Wei, 2005; Zhang et al., 2001; Frame et al., 2002; Zhao et al., 2001; Ishida et al., 1996; Frame et al., 2006). Two of the key factors in transformation efficiency are host genotype and medium components. Maize remains highly recalcitrant to $A$. tumefaciens-mediated transformation, but genotype $\mathrm{A} 188$, $\mathrm{Hi}$ hybrid and $\mathrm{H} 99$ are three genotypes recommended for successful transformation (Zhao et al., 2001; Ishida et al., 1996; Negrotto et al., 2000). Although there is an increasing interest in elite genotypes or hybrids, inbred line $\mathrm{A} 188$ or derivatives of $\mathrm{A} 188$ remain the line of choice for $A$. tumefaciens-mediated transformation. This is because type or friable embryogenic callus is easily produced from these lines. Furthermore, A188 is a model genotype widely used in A. tumefaciensmediated transformation, with a reported transformation frequency of 5 to $50 \%$ (Ishida et al., 1996; Ishida et al., 2007).

Medium components are also key factors in successful transformations. Many basal media, including N6, MS, LS and $D$ media have been used in maize transformation (Vega et al., 2008; Frame et al., 2006; Ishida et al., 2007; Yang et al., 2001). Previous studies determined that antioxidant supplemented media, such as L-cysteine, DTT and PVP (polypyrrolidone), and low salt concentration media, improved $A$. tumefaciens-mediated transformation frequency in several crops species (Perl et al., 1996; Olhoft and Somers, 2001; Paz et al., 2004). However, few reports of transformation efficiency using multiple factors and the interactive effects of these factors are available for maize.

In the present study, the effects of antioxidants, basal media, salt concentration and copper sulfate on transformation efficiency was evaluated, and focused was also on optimizing these factors to establish a high-frequency transformation system in maize.

\section{MATERIALS AND METHODS}

\section{Plant material}

The maize inbred line, A188, was used as initial material and cultivated on the Agronomy farm at China Agricultural University, Beijing, China. Following self-pollination at approximately $9-12$ days, the ears were collected and sterilized with $70 \%$ ethanol for 5 min. Kernels of normal and healthy morphology were sampled for the study. Immature embryos approximately 1.0 to $1.5 \mathrm{~mm}$ in length were isolated.

\section{Agrobacterium strain and vector}

Agrobacterium strain LBA4404 (Hoekema et al., 1983) was used to harbor a standard binary vector pCAMBIA3301 (CAMBIA, Australia) that contained a CaMV35s promoter-bar and a CaMV35s promotergus-intron reporter gene cassette (Figure 1). Bar was used as the selectable marker gene and uidA (GUS) included an intron as the reporter gene in the binary vector. The pCAMBIA3301 vector was mobilized into Agrobacterium by a direct DNA transfer method (An et al., 1988) and its integrity in Agrobacterium cells was confirmed 
Table 1. Media composition used in Agrobacterium-mediated transformations.

\begin{tabular}{|c|c|}
\hline Infection medium ${ }^{a}$ & $\begin{array}{l}\text { N6, MS, LS , D medium basal salt and their vitamin, } 68.5 \mathrm{~g} / \mathrm{l} \text { sucrose, } 36.0 \\
\mathrm{~g} / \mathrm{l} \text { glucose, } 0.7 \mathrm{~g} / \mathrm{l} \mathrm{L}-\mathrm{proline}, 0.1 \mathrm{~g} / \mathrm{l} \text { myo-inositol, } 0.5 \mathrm{~g} / \mathrm{l} \mathrm{MES}, 2.0 \mathrm{mg} / \mathrm{l} \\
2,4-\mathrm{D}, \mathrm{pH} 5.2 . \text { Add } 100 \mu \mathrm{M} \text { acetosyringone }{ }^{\mathrm{a}} \text { before using. }\end{array}$ \\
\hline Co-cultivation medium & $\begin{array}{l}\text { Infection medium without glucose, reduce sucrose to } 30 \mathrm{~g} / \mathrm{l} \text { and } \\
\text { supplemented with } 0.05 \mu \mathrm{M} \text { copper sulfate, } 0.4 \mathrm{~g} / \mathrm{l} \mathrm{L} \text {-cysteine }{ }^{\mathrm{a}}, 0.15 \mathrm{~g} / \mathrm{l} \\
\text { DTT }^{\mathrm{a}}, 8 \mathrm{~g} / \mathrm{l} \text { agar, } 100 \mu \mathrm{M} \text { acetosyringone }{ }^{\mathrm{a}}, \mathrm{pH} 5.8 \text {. }\end{array}$ \\
\hline Resting medium & $\begin{array}{l}\text { Cocultivation medium without copper sulfate, L-cysteine }{ }^{\mathrm{a}} \text { and } \text { DTT }^{\mathrm{a}} \text {, } \\
\text { supplemented with } 0.85 \mathrm{mg} / \mathrm{l} \text { silver nitrate }{ }^{\mathrm{a}} \text { and } 0.1 \mathrm{~g} / \mathrm{l} \text { carbenicillin }{ }^{\mathrm{a}}, 2.5 \\
\mathrm{~g} / \mathrm{l} \text { gelrite, } \mathrm{pH} 5.8 \text {. }\end{array}$ \\
\hline Selection medium & Resting medium supplemented with $2.0 \mathrm{~g} / \mathrm{l}$ bialaphos, $\mathrm{pH} 5.8$. \\
\hline Regeneration medium & $\begin{array}{l}\text { MS basal salt and vitamin, supplemented with } 30 \mathrm{~g} / \mathrm{l} \text { sucrose, } 0.1 \mathrm{~g} / \mathrm{l} \text { myo- } \\
\text { inositol, } 3.5 \mathrm{mg} / \mathrm{l} 6-\mathrm{BA}, 3.0 \mathrm{~g} / \mathrm{l} \text { gelrite, } \mathrm{pH} 5.8 \text {. }\end{array}$ \\
\hline Rooting medium & $\begin{array}{l}\text { MS basal salt and vitamin, supplemented with } 25 \mathrm{~g} / \mathrm{l} \text { sucrose, } 0.5 \mathrm{mg} / \mathrm{l} \\
\mathrm{NAA}, 1.2 \mathrm{~g} / \mathrm{l} \text { gelrite, } \mathrm{pH} 5.8 \text {. }\end{array}$ \\
\hline
\end{tabular}

${ }^{a}$ Infection medium, acetosyringone, L-cysteine, DTT, silver nitrate carbenicillin and bialaphos were filter sterilized.

by restriction enzyme analysis.

\section{Medium}

N6, MS, LS and D media were chosen and the compositions are listed in Table 1. Methods followed Ishida et al. (2007) and Vega et al. (2008) with several modifications, including: (1) The addition of $\mathrm{CuSO}_{4}$, L-cysteine and DTT into the co-cultivation medium; (2) Replacing cefotaxime by carbenicillin in the resting and selection media; (3) Supplementing with silver nitrate in co-cultivation, resting and selection media; (4) Autoclaving basal salt, sucrose and glucose; and (5) Filter-sterilizing infection medium, antioxidants, vitamins and antibiotics.

\section{Transformation procedure}

Agrobacterium cells were incubated at $19^{\circ} \mathrm{C}$ for 3 days in YP solid medium. The pre-infection preparation, bacterium inoculation, cocultivation, selection and plant regeneration were conducted according to Ishida et al. (2007). Isolated immature embryos were immersed in $1.5 \mathrm{ml}$ liquid infection medium in a $2.0 \mathrm{ml}$ microcentrifuge tube. The medium was removed and replaced with $1.5 \mathrm{ml}$ fresh liquid infection medium when approximately 200 immature embryos were collected. The tube with collected immature embryos was centrifuged at $20,000 \mathrm{~g}$ at $4^{\circ} \mathrm{C}$ for $10 \mathrm{~min}$. The supernatant was subsequently replaced by $1 \mathrm{ml}$ Agrobacterium suspension (OD660 $=1.0)$. The tube was vortexed and the isolated immature embryos were incubated for $5 \mathrm{~min}$ at room temperature. Infected embryos were plated with scutellum side up on co-cultivation medium, which was overlaid by a piece of sterile filter paper. Following 3 days of incubation at $19^{\circ} \mathrm{C}$ in the dark, the embryos were transferred to a resting medium and incubated at $25^{\circ} \mathrm{C}$. The following 7 days, all embryos were transferred into a selection medium containing 1.5 $\mathrm{mg} / \mathrm{l}$ bialaphos. After 3 weeks, bialaphos was increased to $2.0 \mathrm{mg} / \mathrm{l}$ for 6 weeks to strengthen selection, followed by $2.5 \mathrm{mg} / \mathrm{l}$ bialaphos for 6 weeks. After 2 months, emergent resistant calli were transferred to a regeneration medium and incubated at $25^{\circ} \mathrm{C}$ under a $16 / 8 \mathrm{~h}$ (light/dark) photoperiod. Plantlets regenerated from the resistant callus within 2 - 3 weeks were transferred to a tube containing rooting medium. Plantlets with fully-grown roots were transplanted into soil and grown under greenhouse conditions.

\section{Histochemical GUS assays}

GUS assays were conducted on infected immature embryos after 3 days of co-cultivation (Jefferson et al., 1987). One hundred infected immature embryos were randomly chosen for each assay and three replicates were conducted. Ten resistant calli and shoots which developed from resistant callus were also submitted for assay. The frequency of transient GUS expression (\%) was determined as the percentage of the number of infected immature embryos that exhibited GUS staining after 3 days of co-cultivation. The transformation frequency (\%) was the percentage of the number of positive transgenic plants against the total number of immature inoculated embryos.

\section{Transgene analysis}

Total genomic DNA from regenerated plant leaves was extracted following the CTAB isolation procedure (Saghai-Maroof et al., 1984), and used for polymerase chain reaction (PCR) and Southern blot analysis. PCR primers for the bar genes were forward primer: 5'-ACTTCAGCAGGTGGGTGTAGAGCGT-3' and reverse primer: 5'GCACCATCGTCAACCACTACATCGA-3'. The PCR parameters included one cycle of $95^{\circ} \mathrm{C} 3 \mathrm{~min} ; 35$ cycles of $95^{\circ} \mathrm{C} 30 \mathrm{~s}, 61^{\circ} \mathrm{C} 30$ $\mathrm{s}, 72^{\circ} \mathrm{C} 45 \mathrm{~s}$ and one cycle of $72^{\circ} \mathrm{C} 10 \mathrm{~min}$; samples were stored at $4^{\circ} \mathrm{C}$. PCR products were $273 \mathrm{bp}$ and separated on $2 \%(\mathrm{w} / \mathrm{v})$ agarose gels. $20 \mathrm{mg}$ of each DNA sample was digested with Sac at $37^{\circ} \mathrm{C}$ overnight. Digested products were fractionated on $0.8 \%$ agarose gels and subsequently transferred to nylon membranes. DNA was fixed to the membrane at $80^{\circ} \mathrm{C}$ for $2 \mathrm{~h}$. The CaMV35s promoter probe was DIG labeled applying PCR and forward primer: 5'-TACCCGAGCAATAATCTCCAGG-3' and reserve primer: 5' CGGCAGAGGCATCTTCAACGA -3'. Southern blot analysis was conducted according to the Roche Southern blot Kit protocol (Roche Applied Science, Mannheim Germany).

Transgenic plants regenerated from resistant calli were selfed or back-crossed to the wild-type A188 plants. For progeny analysis, five sets of progeny were analyzed using PCR assays to examine the bar gene segregation patterns. Progeny segregation analysis of 
Table 2. The effects of media, antioxidants and N6 salts levels on infection frequency.

\begin{tabular}{|c|c|c|c|c|c|c|c|c|c|}
\hline $\begin{array}{l}\text { Type of } \\
\text { medium }\end{array}$ & Treatment & $\begin{array}{l}\text { Number of } \\
\text { infected immature } \\
\text { embryos }\end{array}$ & $\begin{array}{l}\text { Number of } \\
\text { GUS staining } \\
\text { embryos }\end{array}$ & $\begin{array}{lr}\begin{array}{l}\text { Average } \\
\text { frequency }\end{array} & \text { of } \\
\text { transient } & \text { GUS } \\
\text { expression } & \\
\end{array}$ & $\begin{array}{l}\text { Number } \\
\text { infected } \\
\text { immature } \\
\text { embryos }\end{array}$ & $\begin{array}{l}\text { Number of } \\
\text { resistant } \\
\text { callus }\end{array}$ & $\begin{array}{l}\text { Number of } \\
\text { regeneration } \\
\text { plants }\end{array}$ & $\begin{array}{l}\text { Number of } \\
\text { positive } \\
\text { plants }\end{array}$ & $\begin{array}{l}\text { Transformation } \\
\text { frequency }\end{array}$ \\
\hline \multirow{2}{*}{ MS } & 1 & 300 & 113 & $37.7 \pm 5.0$ & 723 & 8 & 7 & 0 & 0.0 \\
\hline & 2 & 300 & 188 & $62.6 \pm 4.5$ & 1132 & 39 & 35 & 23 & 2.0 \\
\hline \multirow{2}{*}{ LS } & 1 & 300 & 121 & $40.3 \pm 4.7$ & 847 & 13 & 10 & 0 & 0.0 \\
\hline & 2 & 300 & 170 & $56.6 \pm 4.1$ & 1498 & 57 & 51 & 33 & 0.9 \\
\hline \multirow{2}{*}{$\mathrm{D}$} & 1 & 300 & 101 & $33.6 \pm 4.5$ & 426 & 5 & 5 & 0 & 0.0 \\
\hline & 2 & 300 & 163 & $54.3 \pm 4.7$ & 792 & 31 & 26 & 14 & 1.8 \\
\hline \multirow{6}{*}{ N6 } & 1 & 300 & 82 & $27.3 \pm 3.5$ & 551 & 6 & 6 & 0 & 0.0 \\
\hline & $10 \%$ & 300 & 295 & $98.3 \pm 0.6$ & 877 & 0 & -- & -- & -- \\
\hline & $30 \%$ & 300 & 287 & $95.6 \pm 1.5$ & 784 & 0 & -- & -- & -- \\
\hline & $50 \%$ & 300 & 278 & $92.6 \pm 3.2$ & 653 & 112 & 107 & 104 & 15.9 \\
\hline & $70 \%$ & 300 & 246 & $82 \pm 4.0$ & 574 & 47 & 44 & 37 & 6.4 \\
\hline & $100 \%$ & 300 & 217 & $72.3 \pm 3.7$ & 872 & 44 & 41 & 28 & 3.2 \\
\hline
\end{tabular}

Treatment $1=$ Absence of $0.4 \mathrm{~g} / \mathrm{l} \mathrm{L}$-cysteine and $0.15 \mathrm{~g} / \mathrm{l}$ DTT.

Treatment 2 = Presence of $0.4 \mathrm{~g} / \mathrm{l} \mathrm{L}$-cysteine and $0.15 \mathrm{~g} / \mathrm{I} \mathrm{DTT}$.

$10,30,50,70$ and $100 \%$ mean levels of $\mathrm{N} 6$ medium basal salts.

the bar gene was statistically analyzed for goodness-of-fit to simple Medelian expectations using a Chi-square test.

\section{RESULTS}

\section{Effects of basal medium and antioxidants}

The absence of $0.4 \mathrm{~g} / \mathrm{l} \mathrm{L-cysteine}$ and $0.15 \mathrm{~g} / \mathrm{I}$ DTT resulted in a decreased frequency of transient GUS expression in N6 medium (27.3\%) compared with LS (40.3\%), MS (37.7\%) and D media (33.7 $\%$ ) (Table 2). GUS activity increased with the addition of both $0.4 \mathrm{~g} / \mathrm{l} \mathrm{L}$-cysteine and $0.15 \mathrm{~g} / \mathrm{l} \mathrm{DTT}$. Among the four different basal media, transient GUS expression improved most with N6 basal medium; $72.3 \%$ infected immature embryos displayed GUS staining, approximately three fold higher than in the absence of L-cysteine and DTT (27.3\%). Consequently, $0.4 \mathrm{~g} / \mathrm{l}$ L-cysteine and $0.15 \mathrm{~g} / \mathrm{l}$ DTT were added to the N6 salt $\mathrm{CO}^{-}$ cultivation medium for subsequent experiments.

Transformation frequency was also affected by basal medium and antioxidants. The inclusion of $0.4 \mathrm{~g} / \mathrm{l}$ L-cysteine and $0.15 \mathrm{~g} / \mathrm{l}$ DTT in the cocultivation medium increased the transformation frequency of the N6 medium (3.2\%) compared to MS $(2.0 \%)$, LS $(0.9 \%)$ and D $(1.8 \%)$ media (Table 2).

\section{Effects of N6 medium under different salt concentrations}

The differences in the frequency of transient GUS expression were exhibited among the five different basal salt levels of N6 medium. The following 3 days of co-cultivation, over $95 \%$ of infected immature embryos displayed GUS staining in 10 and $30 \% \mathrm{~N} 6$ basal salts medium. Unfortunately, most infected immature embryos did not develop further and died, indicating that low salt concentrations in the medium could have negative effects on the embryogenic capacity of immature maize embryos, although salt concentration facilitated high frequency of T-DNA delivery. The frequency of transient GUS expression reached $92.7 \%$ with $50 \%$ N6 basal salts, but with the increased salt concentration, transient GUS expression decrea-sed by $82.0 \%$ in $70 \%$ basal salt and $72.3 \%$ in $100 \%$ basal salts (Table 2). Therefore, salt concentration in basal medium likely affected the transformation frequency and high salt concentration resulted in a low transformation rate. 


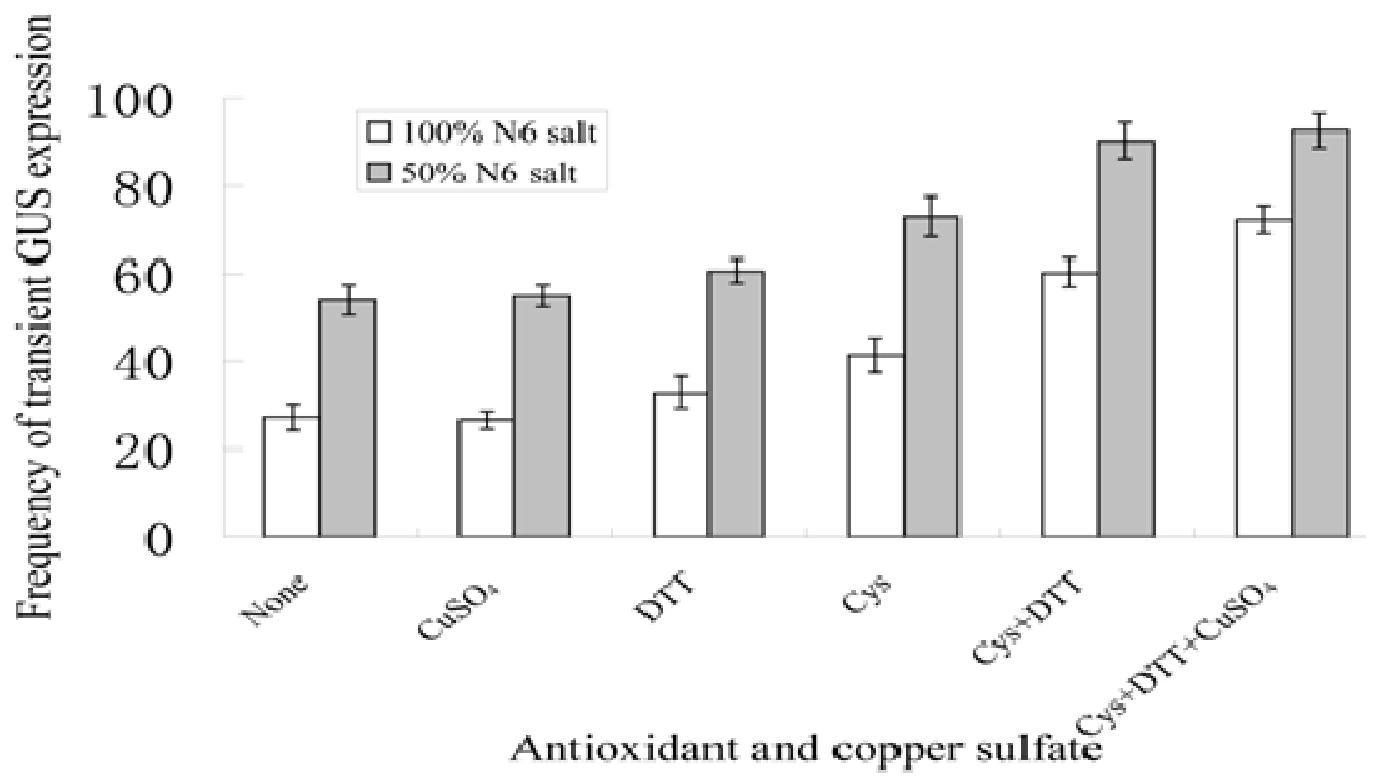

Figure 2. The effects on infection frequency of copper sulfate and antioxidants added to the cocultivation medium. Data shown are mean \pm SE of three experiments; each experiment consisted of $\mathrm{N}$ $=100$. L-cysteine at $0.4 \mathrm{~g} / \mathrm{l}$, DTT at $0.15 \mathrm{~g} / \mathrm{l}$ and copper sulfate at $0.05 \mu \mathrm{M}$.

The application of 50\% N6 salt concentration resulted in a transformation frequency increase as high as $15.9 \%$, followed by $6.4 \%$ with a $70 \%$ salt level and $3.2 \%$ with a $100 \%$ salt concentration (Table 2). These results suggested that basal salt concentration greater than $50 \%$ was not favorable for the transformation process, probably suppressed infection and subsequent integration of TDNA into the plant genome. As a result, a $50 \%$ salt concentration, $0.4 \mathrm{~g} / \mathrm{l}$ L-cysteine, $0.15 \mathrm{~g} / \mathrm{l} \mathrm{DTT}$ and $0.05 \mu \mathrm{M}$ $\mathrm{CuSO}_{4}$ for $A$. tumefaciens-mediated transformation in the system was used.

\section{Effects of individual and combinations of antioxidants and copper sulfate}

In N6 basal salt and absence of copper sulfate cocultivation medium, $27.3 \%$ of the immature embryos displayed GUS staining. However, a copper sulfate supplement of $0.05 \mu \mathrm{M}$ decreased the frequency of transient GUS expression to $26.7 \%$ (Figure 2). Addition of DTT alone resulted in a higher level of GUS expression with $33 \%$ in $100 \%$ N6 salt and $60.7 \%$ in $50 \%$ salt. L-cysteine separately showed an increase in transient GUS expression by $41.3 \%$ in $100 \% \mathrm{~N} 6$ salt and $73 \%$ in $50 \%$ N6 salt, indicating that L-cysteine was more favorable to DTT alone in the co-cultivation medium. The combined use of both L-cysteine and DTT in the co-cultivation medium demonstrated a rise in the level of GUS expression to $60.3 \%$ in $100 \% \mathrm{~N} 6$ salt and $90.3 \%$ in $50 \%$ N6 salt. Including copper sulfate with the combined use of Lcysteine and DTT resulted in higher GUS activity with a transient GUS expression of $72.3 \%$ at a $100 \%$ salt level and $92.7 \%$ at $50 \%$ N6 salt.

Transient GUS expression was not increased at $100 \%$ N6 salt and $\mathrm{CuSO}_{4}$ alone. However, a significant improvement in transient GUS expression was observed when DTT was added alone $(p<0.05)$ (Table 3). Addition of L-cysteine alone and the combination of L-cysteine and DTT in the co-cultivation medium resulted in significant increase in transient GUS expression $(p<$ 0.01 ) (Table 3). Similar results were obtained when $50 \%$ N6 salt concentration was applied to the co-cultivation medium (Table 3).

\section{Transgenic plant recovery and molecular and genetic characterization}

Resistant calli began to emerge from the immature infected embryos following approximately two months of bialaphos selection (Figure 3). The plants regenerated from these calli appeared normal morphologically (Figures $4 a$ and $b$ ). Ten resistant calli and plantlets were randomly chosen for GUS assays, respectively and all samples displayed blue GUS staining (Figures $5 a-c$ ). These results indicated the uidA gene was integrated and expressing in the calli and plantlets.

Total genomic DNA was extracted from leaf material of 332 putative plantlets for PCR analysis. Primer pairs specific to detect the bar gene were employed. 239 of 332 putative plantlets tested positive with $72.0 \%$ selection efficiency (Figure 6), suggesting our three-step selection regime (beginning with $1.5 \mathrm{mg} / \mathrm{l}$ for 3 weeks; increased to 
Table 3. T-test analysis: Effects of different antioxidants and copper sulfate on the frequency of transient GUS expression.

\begin{tabular}{|c|c|c|c|c|c|}
\hline $\begin{array}{c}\text { N6 Salt } \\
\text { concentration }\end{array}$ & Treatment & $\begin{array}{c}\text { Average frequency of } \\
\text { transient GUS } \\
\text { expression }\end{array}$ & Variance & $P$ value & $\begin{array}{c}\text { Significance } \\
\text { level }\end{array}$ \\
\hline \multirow{6}{*}{$100 \%$} & none & $27.33 \pm 3.51$ & 12.33 & & \\
\hline & $\mathrm{CuSO}_{4}$ & $26.67 \pm 2.51$ & 6.33 & 0.401241 & NS \\
\hline & DTT & $33.00 \pm 2.65$ & 7.00 & 0.044696 & * \\
\hline & L-cys & $41.33 \pm 4.51$ & 20.33 & 0.006618 & $* *$ \\
\hline & DTT+L-cys & $60.33 \pm 4.04$ & 3.00 & 0.000218 & ** \\
\hline & $\begin{array}{c}\mathrm{DTT}+\mathrm{L}- \\
\text { cys+CuSO }\end{array}$ & $72.33 \pm 3.79$ & 14.33 & $5.62 \mathrm{E}-05$ & ** \\
\hline \multirow{6}{*}{$50 \%$} & none & $54.00 \pm 3.00$ & 9.00 & & \\
\hline & $\mathrm{CuSO}_{4}$ & $55.00 \pm 2.00$ & 4.00 & 0.328023 & NS \\
\hline & DTT & $60.67 \pm 3.51$ & 12.33 & 0.033383 & * \\
\hline & L-cys & $73.00 \pm 4.00$ & 16.00 & 0.0013794 & $\star *$ \\
\hline & $\mathrm{DTT}+\mathrm{L}-\mathrm{cys}$ & $90.33 \pm 3.21$ & 10.33 & $6.92258 \mathrm{E}-05$ & $* *$ \\
\hline & $\begin{array}{c}\mathrm{DTT}+\mathrm{L}- \\
\mathrm{cys}+\mathrm{CuSO}_{4} \\
\end{array}$ & $92.67 \pm 3.21$ & 10.33 & 5.42E-05 & $* *$ \\
\hline
\end{tabular}

100 and $50 \%$ N6 basal salts were used in co-cultivation medium for every treatment. Data shown are mean \pm SE of three experiments; each experiment included $\mathrm{N}=100$. L-cysteine at $0.4 \mathrm{~g} / \mathrm{l}$, DTT at $0.15 \mathrm{~g} / \mathrm{l}$ and copper sulfate at $0.05 \mathrm{mM}$.

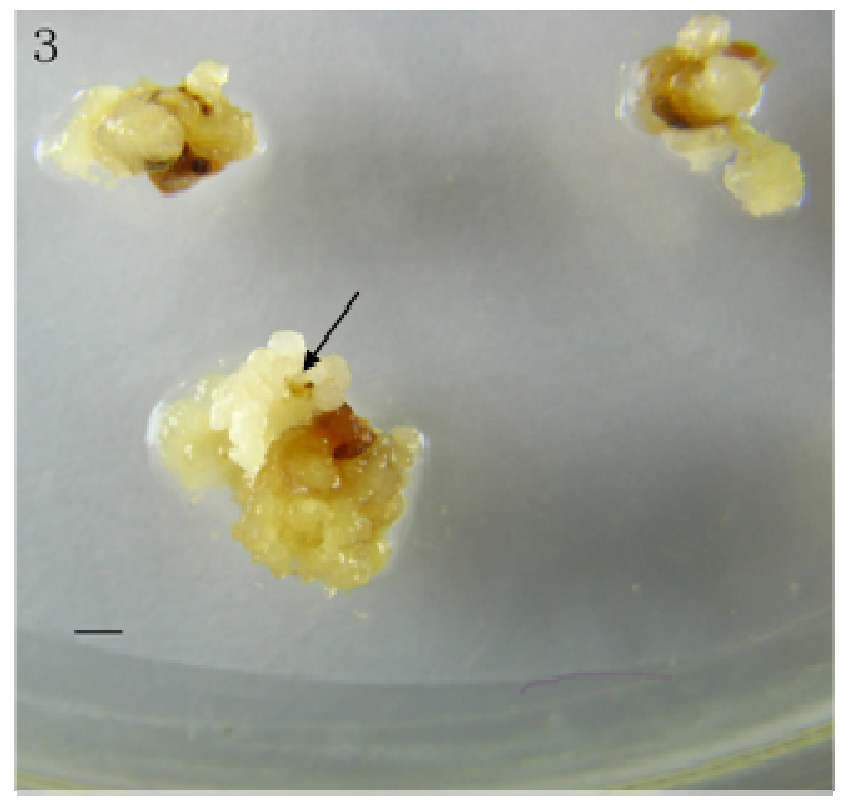

Figure 3. Resistant embryogenic callus emergent from an immature maize embryo A188 showing vigorous growth on selective medium with $2.5 \mathrm{mg} / \mathrm{l}$ bialaphos (scale bar $=1 \mathrm{~mm}$ ).

$2.0 \mathrm{mg} / \mathrm{l}$ for 6 weeks and $2.5 \mathrm{mg} / \mathrm{l}$ for 6 weeks) resulted in a low escape rate.

Six genomic DNA samples were obtained from PCR positive plants and used for Southern blot analysis. Figure 7 indicates that four transgenic plants possessed a single copy of the transgene; one possessed two copies of the transgene, revealing that the T-DNA was successfully integrated into the genome, and the different banding patterns suggested each was from independent transgenic events.

Five transgenic events with large numbers of seeds were chosen to examine bar gene segregation in the progeny. Two transgenic events (T83 and T141) were selfed and three events (T127, T189 and T206) were backcrossed to the wild-type A188 plants. T83 and T141 displayed a 3:1 segregation ratio and T127, T189 and T206 displayed a 1:1 ratio, which indicated the presence of single locus integration in all five transgenic lines (Table 4).

\section{DISCUSSION}

Maize transformation frequency has primarily been affected by basal medium in $A$. tumefaciens-mediated transformation (Ishida et al., 1996; Frame et al., 2006). However, to date the reason for this limitation is not well understood. The production of type or friable embryogenic callus from maize immature embryos is clearly related to the nature of the basal medium, and the efficiency of embryogenic callus formation is different when various basal media are used (Armstrong and Green, 1985; Ducan et al., 1985; Carvalho et al., 1997). The present results demonstrated that for maize A188 inbred line, LS medium performed better than N6 medium when L-cysteine and DTT were absent from the cocultivation medium. This result is consistent with that reported by Ishida et al. (1996). However, when a 50\% 


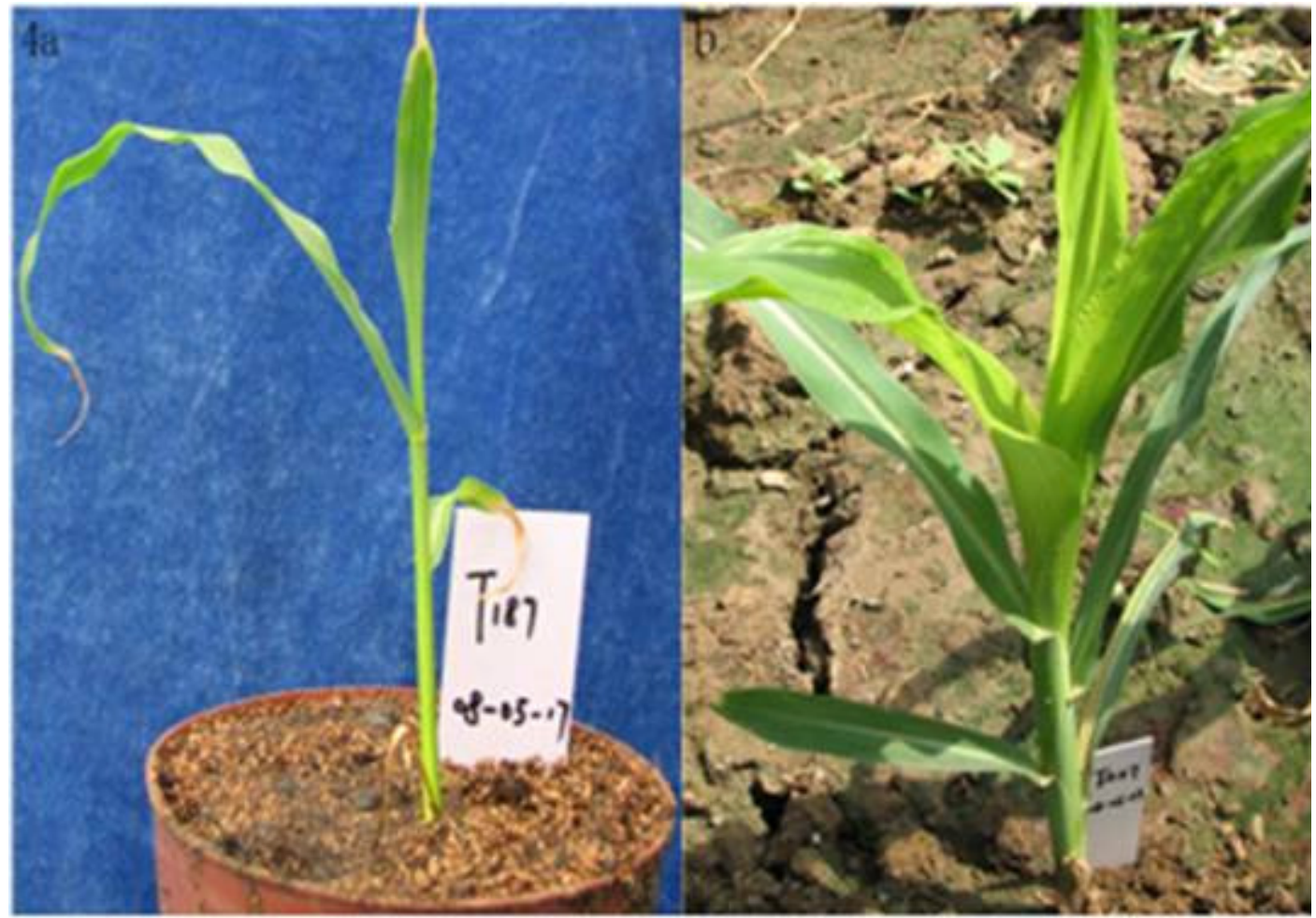

(a)

(b)

Figure 4. The regenerated transgenic plants transferred to soil. a: Transgenic plant $\left(T_{0}\right)$ transferred from tissue culture to pot. $\mathbf{b}$ : Transgenic plant grown in the field and under greenhouse conditions.

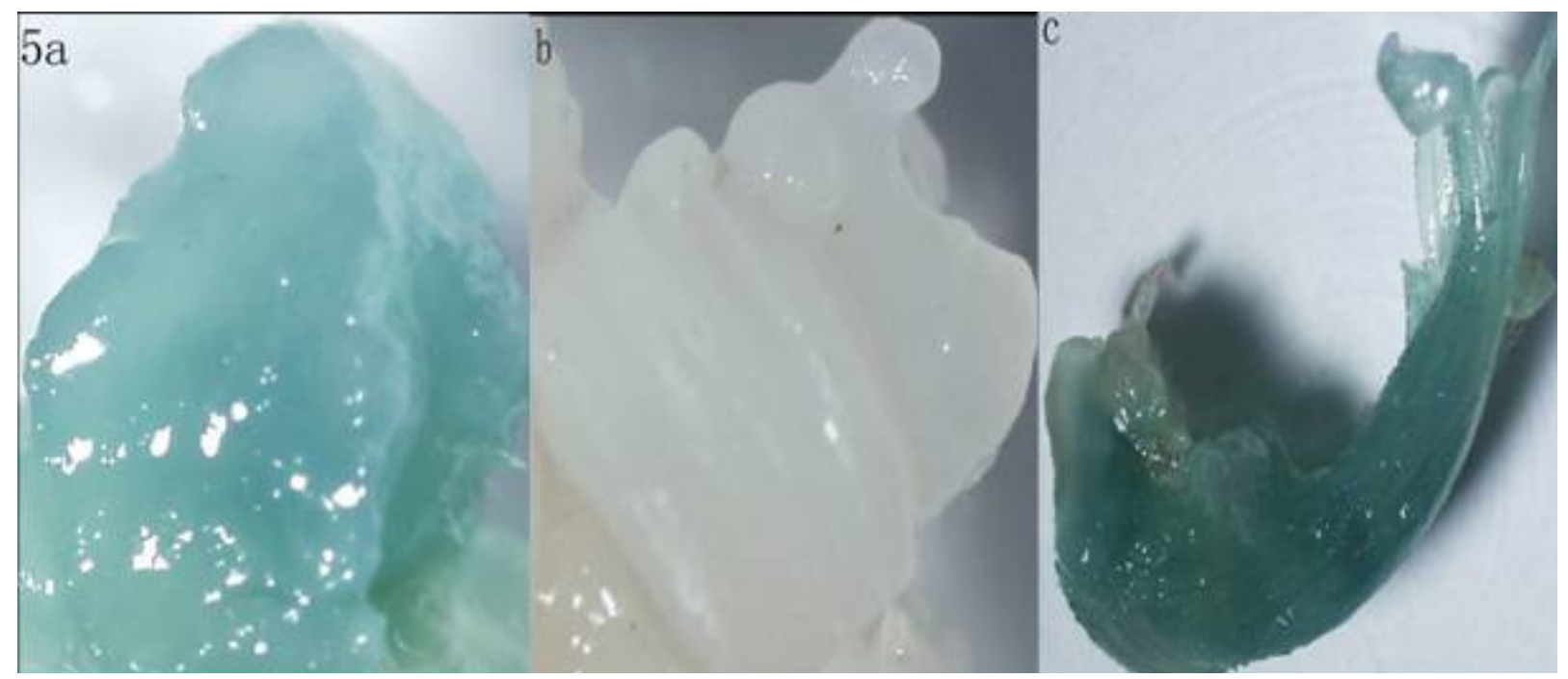

Figure 5. Stable GUS expression was observed in resistant callus and shoots. a: Bialaphos resistant callus. b: Normal A188 callus (control). c: Shoot regenerated from resistant callus.

instead of full strength basal salt was used in conjunction with both $0.4 \mathrm{~g} / \mathrm{l} \mathrm{L-cysteine} \mathrm{and} 0.15 \mathrm{~g} / \mathrm{l}$ DTT in the cocultivation medium, a high frequency of transient GUS expression was observed and transgenic plants were obtained from N6 basal medium. These results are incongruent from those reported by Ishida et al. (1996), who showed that no positive transgenic plants were obtained when using $\mathrm{N} 6$ as a basal medium. In addition, 


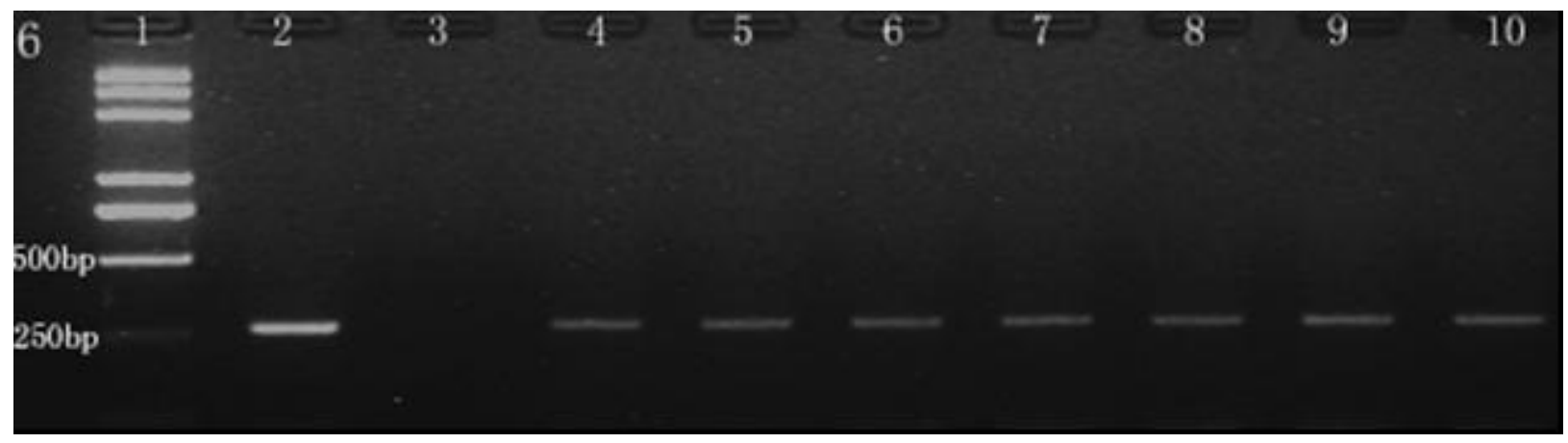

Figure 6. PCR amplification using bar primers. Lane 1: DL2000 plus DNA maker. Lane 2: Plasmid DNA. Lane 3: Nontransgenic plant. Lanes 4 - 10: transgenic plants.

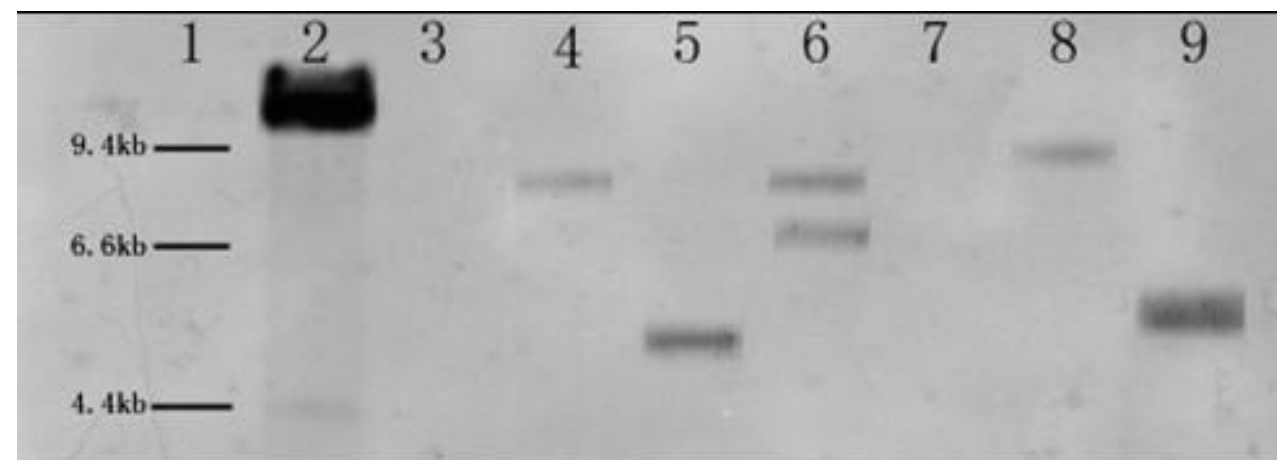

Figure 7. Southern-blot analysis of transformed plants. Lane 1: $\lambda \mathrm{DNA} /$ Hind maker. Lane 2 : pCAMBIA3301 digested with Sac. Lane 3: Non-transgenic plant. Lane 4 - 6 and 8 - 9: Different PCR-positive plants. Lane 7: False PCR-positive plant.

Table 4. Progeny segregation analysis of primary transgenic A188 maize events.

\begin{tabular}{|c|c|l|c|c|c|c|}
\hline Events & Total progeny & Selfing or back crossing & Positive & Negative & Segregation ratio & $\mathbf{X}^{2}$ \\
\hline T83 & 39 & Selfing & 28 & 11 & $3: 1$ & 0.214 \\
T127 & 52 & Back crossing & 24 & 28 & $1: 1$ & 0.308 \\
T141 & 26 & Selfing & 19 & 7 & $3: 1$ & 0.051 \\
T189 & 91 & Back crossing & 44 & 47 & $1: 1$ & 0.099 \\
T206 & 63 & Back crossing & 29 & 34 & $1: 1$ & 0.397 \\
\hline
\end{tabular}

$x^{2}=3.84(0.05,1 d f)$.

antioxidants were integral in $A$. tumefaciens-mediated transformation of maize (Frame et al., 2002, 2006; Vega et al., 2008). The role of antioxidants may minimize cell death caused by a hypersensitive response (Frame et al., 2002). This may enable increased survival and embryogenesis of infected embryogenic-competent cells, resulting in improved transformation frequency. In the system used in this study, $0.4 \mathrm{~g} / \mathrm{l} \mathrm{L}$-cysteine and $0.15 \mathrm{~g} / \mathrm{l} \mathrm{DTT}$ as a supplement to the $\mathrm{N} 6$ co-cultivation medium resulted in increased transformation frequency.

Gao and Bao (2004) found that salt concentration influenced gene transfer by influencing $A$. tumefaciens growth. However, the reason transformation frequencies improved under low concentration remains unclear. Most GUS staining appeared on the embryo axis sides and the edges when a $100 \% \mathrm{~N} 6$ basal salt concentration was used in the co-cultivation medium. However, more than $50 \%$ GUS staining displayed in the scutellum area when the salt concentration was below $50 \%$ (data no show). Callus is typically derived from the scutellum area of immature embryos and rarely from the axis side or edges. This likely explains why the transformation frequency was improved in low salt concentrations. However, very low salt concentrations of 10 and $30 \%$ exhibited negative effects on transformation frequency. Infected immature embryos severely damaged, did not 
grow further into embryogenic calli, and consequently no resistant calli were recovered. N6 medium with $50 \%$ salt concentration showed the highest frequency of transient GUS expression, and also facilitated further development of infected immature embryos without negative impact, resulting in increased transformation efficiency.

\section{ACKNOWLEDGEMENTS}

The authors are grateful to Drs. Zhang Zuxin and Qin Feng for their critical reading of the manuscripts.

\section{REFERENCES}

An G, Ebert PR, Mitra A, Ha SB (1988). Binary vectors. In: Gelvin SB, Schilperoot RA (ed) Plant Mol Biology Manual, Martinus Nijhoff, Dordrecht, The Netherlands, A3: 1-19

Armstrong CL, Green CE (1985). Establishment and maintenance of friable, embryogenic maize callus and the involvement of L-proline. Planta, 164: 207-214.

Carvalho CHS, Bohorova N, Bordallo PN, Abreu LL, Valicente FH, Bressan W, Paiva E (1997). Type $\alpha$ callus production and plant regeneration in tropical maize genotypes. Plant Cell Rep. 17: 73-76.

Cheng M, Fry JE, Pang S, Zhou H, Hironaka CM, Duncan DR, Conner TW, Wan Y (1997). Genetic transformation of wheat mediated by Agrobacterium tumefaciens. Plant physiol. 115: 971-980.

Ducan DR, Williams ME, Zehr BE, Widholm JM (1985). The production of callus capable of plant regeneration from immature embryos of numerous Zea mays genotypes. Planta, 165: 322-332.

Frame BR, McMurray JM, Fonger TM, Main ML, Taylor KW, Torney FJ, Paz MM, Wang K (2006). Improved Agrobacterium-mediated transformation of three maize inbred lines using MS salts. Plant Cell Rep. 25: 1024-1034.

Frame BR, Shou H, Chikwamba RK, Zhang Z, Xiang C, Fonger TM, Pegg SEK, Li B, Nettleton DS, Pei D, Wang K (2002). Agrobacterium tumefaciens-mediated transformation of maize embryos using a standard binary vector system. Plant physiol. 129: 13-22.

Gao LP, Bao MZ (2004). Optimization of the uidA gene transfer of Rosa hybrida via Agrobacterium tumefaciens: an assessment of factors influencing the efficiency of gene transfer. Forestry Studies China, 6(3): 9-14.

Gordon-Kamm WJ, Spencer TM, Magano ML, Adams TR, Daines RJ, Start WG (1990). Transformation of maize cells and regeneration of fertile transgenic plants. Plant Cell, 2: 603-618.

Gore MA, Chia JM, Elshire RJ, Sun Q, Ersoz ES, Hurwitz BL, Peiffer JA, McMullen MD, Grills GS, Ross-lbarra J, Ware DH, Buckler ES (2009). A first-generation haplotype map of maize. Science, 326: 1115-1117.

Hansen G, Wright MS (1999). Recent advances in the transformation of plants. Trends Plant Sci. 4: 226-231.

Hernalsteens JP, Thia-Toong L, Schell J, Van Montagu M (1984). An Agrobacterium-transformed cell culture from monocol Asparagus sooicinalis. EMBO J. 3(13): 3039-3041.

Hiei Y, Ohta S, Komari T, Kumashiro T (1994). Efficient transformation of rice (Oryza sativa L.) mediated by Agrobacterium and sequence analysis of the boundaries of the T-DNA. Plant J. 6: 271-282.
Hoekema A, Hirsch PR, Hooykaas PJJ, Schilperoort RA (1983). A binary plant vector strategy based on separation of vir and $T$ region of Agrobacterium tumefaciens Ti-plasmid. Nature, 303: 179-180.

Hooykaas-Van slogteren GMS, Hooykaas PJJ, Schiperool RA (1984). Expression of Ti plasmid genes in monocotyledonous plants infected with Agrobacterium tumefaciens. Nature, 311: 763-764.

Huang XQ, Wei ZM (2005). Successful Agrobacterium-mediated genetic transformation of maize elite inbred lines. Plant Cell, Tissue Organ Cult. 83: 187-200.

Ishida Y, Hiei Y, Komari T (2007). Agrobacterium-mediated transformation of maize. Nat. Protoc. 2(7): 1614-1621.

Ishida Y, Saito H, Ohta S, Hiei Y, Komari T, Kumashiro T (1996). High efficiency transformatiom of maize (zea mays L.) mediated by Agrobacterium tumefaciens. Nat. Biotechnol. 14: 745-750.

Jefferson RA, Kavanagh TA, Bevan MW (1987). GUS fusions: $\beta$ glucuronidase as a sensitive and versatile gene fusion marker in higher plants. EMBO J. 6: 3901-3907.

Negrotto D, Jolley M, Beer S, Wenck AR, Hansen G (2000). The use of phosphomannose-isomerase as a selectable marker to recover transgenic maize plants (Zea mays L.) via Agrobacterium transformation. Plant Cell Rep. 19: 798-803.

Olhoft P, Somers D (2001). L-cysteine increase Agrobacteriummeidated T-DNA delivery into soybean cotyledonary-node cells. Plant Cell Rep. 20: 706-711.

Paz MM, Shou HX, Guo ZB, Zhang ZY, Banerjee AK, Wang K (2004). Assessment of conditions affecting Agrobacterium-mediated soybean transformation using the cotyledonary node explant. Euphytica, 136 167-179.

Perl A, Lotan O, Abu-Abied M, Holland D (1996). Establishment of an Agrobacterium-mediated transformation system for grape (Vitis vinifera L.): the role of antioxidants during grape-Agrobacterium interactions. Nat. Biotechnol. 14: 624-628.

Register JC, Peterson DJ, Bell PJ, Bullock WP, Evans IJ, Frame B, Greenland AJ, Higgs NS, Jepson I, Jiao SP, Lewnau CJ, Sillick JM, Wilson HM (1994). Structure and function of selectable and nonselectable transgenes in maize after introduction by particle bombardment. Plant Mol. Biol. 25: 951-961.

Saghai-Maroof MA, Soliman KM, Jorgensen RA, Allard RW (1984). Ribosomal DNA spacer-length polymorphisms in barley: Mendelian inheritance, chromosomal location, and population dynamics. Proc. Natl. Acad. Sci. USA, 81: 8014-8018.

Shou H, Fram BA, Whitham SA, Wang K (2004). Assessment of transgenic maize events produced by particle bombardment of Agrobacterium-mediated transformation. Mol. Breed. 13: 201-208.

Tingay S, McElroy D, Kalla R, Fieg S, Wang M, Thornton S, Brettell R (1997). Agrobacterium tumefaciens-mediated barley transformation. Plant J. 11: 1369-1376.

Vega JM, Yu WC, Kennon AR, Chen XL, Zhang ZY (2008). Improvement of Agrobacterium-mediated transformation in $\mathrm{Hi}-\alpha \alpha$ maize (Zea mays) using standard binary vectors. Plant Cell Rep. 27: 297-305.

Yang H, Wang GY, Dai JR (2001). Transformation of maize elite inbred lines. J. Agric. Biotechnol. 9(4): 334-337.

Zhang R, Wang GY, Zhang XH, Zhao HJ (2001). Agrobacterium tumefaciens mediated maize transformation. J. Agric. Biotechnol. 9(1): 45-48.

Zhao ZY, Gu WN, Cai TS, Tagliani L, Hondred D, Bond D, Schroeder S, Rudert M, Pierce D (2001). High throughput genetic transformation mediated by Agrobacterium tumefaciens in maize. Mol. Breed. 8: 323-333. 